\title{
Glycoprotein assay based on the optimized immittance signal of a redox tagged and lectin-based receptive interface
}

\author{
Adriano Santos, Paulo R. Bueno* \\ Universidade Estadual Paulista "Júlio de Mesquita Filho" (São Paulo State University), Institute of Chemistry, Physical Chemistry Department, Nanobionics \\ Group, 55 Prof. Francisco Degni Street, Quitandinha, 14800-060 Araraquara, São Paulo, Brazil
}

\section{A R T I C L E I N F O}

\section{Article history:}

Received 16 February 2016

Received in revised form

8 April 2016

Accepted 14 April 2016

Available online 16 April 2016

Keywords:

Electroanalysis

Electrochemical impedance spectroscopy

Glycoprotein

Lectin

Immittance functions

\begin{abstract}
A B S T R A C T
Glycoproteins play important roles in biological systems such as in process related to cell binding, signaling and disease. Consequently, novel, potentially quantitative, and rapid electroanalytical approaches capable of detecting protein binding are welcome. Herein, we introduce a methodology that is both fast and sensitive, and capable of quantification of the binding affinity in glycoprotein-lectin molecular models. The proposed methodology is based on the electrochemical impedance spectroscopy technique focused on the immittance function approach, wherein a library of analytical parameters can be computed from the raw impedance data obtained, and automatically processed in a label-free, quantifiable and very sensitive assay platform. This approach also avoids redox probe pre-doping of the analytical sample.

Avoiding redox pre-doping of the analytical sample is achievable designing an appropriate redoxtagging monolayer containing lectin interface (a carbohydrate binding protein, herein ArtinM) as the bioreceptor, endowing high sensitivity of electrochemical signal when specifically detecting glycoproteins of interest (presently horseradish peroxidase, HRP, a mannose glycoprotein) as the biochemical target for ArtinM. The electroanalytical curves demonstrated that the binding affinity constant could be evaluated as equivalent for all library (immittance function) parameters, allowing optimized single frequency (or a range of frequencies) assessment with high sensitivity. In other words, binding affinity constants between ArtinM and HRP for each of the parameters in the immittance function library at given optimized frequencies were similar, independently of the parameter. Thus, the feasibility of using this immittance function approach for electroanalytical glycoarrays by accessing bio-recognition processes on a rapid (optimized) single frequency and highly multiplexable platform was demonstrated.
\end{abstract}

(c) 2016 Elsevier B.V. All rights reserved.

\section{Introduction}

Glycoproteins and glycolipids are complex carbohydrate-containing chemical structures that play important roles in biological systems (Dwek, 1996; Nelson and Cox, 2012). Among numerous biological processes, carbohydrate units have vital importance in biochemical activities, for instance, in controlling physicochemical phenomena related to protein adsorption/interaction or binding (cell-cell and biomolecule-cell) that involve cell-signaling (Zachara and Hart, 2006) and pathogen invasion (Marchant et al., 2012). The carbohydrates present in glycoproteins are also associated with protein stability (folding and structure conformation) (Laurent et al., 2008) and abnormal alterations in glycosylation patterns are related with various diseases (Dennis et al., 1999) including

\footnotetext{
* Corresponding author.

E-mail address: prbueno@iq.unesp.br (P.R. Bueno).

URL: http://www.nanobionics.pro.br (A. Santos).
}

diabetes (Dias and Hart, 2007), neurodegenerative disorders (Dias and Hart, 2007), cancer (Adamczyk et al., 2012), and metastasis (Silva, 2015). Indeed several cancer protein biomarkers (proteins related to trauma, infections, and disease onset or progression (Mayeux, 2004; Strimbu and Tavel, 2010)) are glycoproteins presenting with aberrant changes in carbohydrate content such as the prostatic specific antigen (PSA, for prostatic cancer) and CA125 (for ovarian cancer) (Adamczyk et al., 2012; Silva, 2015). Accordingly, the methods for both carbohydrate/glycoprotein detection and qualification/quantification of carbohydrate/glycoprotein-protein/ cell interaction are greatly studied in literature (Pierce et al., 1999; Laurent et al., 2008; Yakovleva et al., 2010; Safina et al., 2011; Bertok et al., 2013a, 2013b; Carvalho et al., 2014; Santos et al., 2014a; Surinova et al., 2015).

Early detection of cancer biomarkers is highly desirable in clinical applications since it increases patient survival rate as a consequence of raising the probability of successful treatment. Several techniques have been developed in order to either validate or detect such biomarkers in early disease stages (Bohunicky and 
Mousa, 2011; Reddy et al., 2012; Uludag and Tothill, 2012; Chiriaco et al., 2013; Asav and Sezgintürk, 2014; Taleat et al., 2014; Yang et al., 2014; Johari-Ahar et al., 2015) by non-invasive methods which are alternative for biopsy. For example, Surinova et al. (2015) described a mass spectrometry methodology to screen and validate a set of glycoproteins for colorectal cancer (CRC) diagnosis and Safina et al. (2011) developed a surface plasmon resonance (SPR) assay for glycoprotein screening. Furthermore, traditional and commercial immunoassays such as ELISA and radioimmunoassay (Voller et al., 1978; Berson and Yalow, 2006), although essentially label-based approaches are extensively used in clinical applications and glycoarrays (Laurent et al., 2008). Nonetheless, ELISA and radio-based immunoassays have the inconvenience of being highly and typically time-consuming (Voller et al., 1978; Luo and Davis, 2013) or costly (Luo and Davis, 2013), and are difficult to be developed for bedside applications (Rusling et al., 2010), and require well-trained technical staff (Wang, 2006). Several label-free bioassays have been extensively explored as an alternative. Some of these assays include piezoelectric ( $\mathrm{Su}$ et al., 2013), optical (Reddy et al., 2012) and electrochemical assays (Ronkainen et al., 2010; Luo and Davis, 2013). Among assays based on electroanalytical signals, electrochemical impedance-based bioassays (electrochemical impedance/capacitance spectroscopy, EIS/ECS) are receiving special attention due their sensitivity, labelfree multiplexing, and miniaturizing capabilities (Daniels and Pourmand, 2007; Lisdat and Schäfer, 2008; Santos et al., 2014b).

Two main different real-time and label-free techniques have been used in quantifying lectin-glycoprotein binding interactions such as isothermal titration calorimetry (ITC) (Pierce et al., 1999; Dam and Brewer, 2002; Takeda and Matsuo, 2014) and quartz crystal microbalance (QCM) (Speight and Cooper, 2012). The advantage of these techniques is the capability to investigate interaction kinetics in real-time (Lebed et al., 2006; Pedroso et al., 2008; Pesquero et al., 2010). This technique can also incorporate analysis of the energy dissipation factor (QCM-D), additionally allowing investigation of the viscoelastic properties of proteinprotein binding/interactions (Höök and Kasemo, 2007), eventually associated with different binding processes or recognition events (Giménez-Romero et al., 2013; Santos et al., 2015a). Similar to QCM, Surface Plasmon Resonance (SPR) is a technique in which the transducing signal is intrinsically and related to changes in the optical properties of the investigated receptive surface. It allows detection of changes in the optical properties as a consequence of protein adsorption that can be applied in affinity studies (Homola et al., 1999; Laurent et al., 2008; Safina et al., 2011). Nonetheless, the development of glycoarrays based either QCM or SPR is time-consuming, presenting with higher cost and lower sensitivity compared to competing electroanalytical techniques such as impedance electrochemical assays (Carvalho et al., 2014; Santos et al., 2014a).

Impedance-based bioassays comprise mostly of two different methods: faradaic and non-faradaic (Daniels and Pourmand, 2007; Lisdat and Schäfer, 2008; Santos et al., 2014b). In both these approaches of impedance-based bioassays, useful analytical information is generally obtained only after applying the equivalent circuit analysis (for instance, by using a Randles equivalent circuit) to fit/adjust the raw impedance spectra data to an appropriated circuit model (Daniels and Pourmand, 2007; Lisdat and Schäfer; 2008; Santos et al., 2014b). Faradaic assays necessarily use redox probes in the analytical solution to generate the electrochemical transducer signal of interest, which is further related to and quantified by the specific binding of the analyte. The major charge transducer signal of interest is associated with the change of the charge transfer resistance ( $\left.R_{c t}\right)$, which is expected to rise as the target concentration in the analytical solution increases. This expectative comes from the fact that in capturing the target by the receptive interface a more effective isolating layer (to those electroactive ionic species doping/added to the solution phase) is formed as the binding event occurs so that the increasing in $R_{c t}$ is as consequence of a chemical (steric) blocking of the interface.

On the other hand, in non-faradaic based assays, the redox probe is not required since the transduction signal is capacitive, and primarily originates from changes in the dielectric (double layer-like) properties of the interface (Berggren et al., 2001; Goes et al., 2012). In non-faradaic assays, charge distribution is mainly caused by ionic relaxation effects and ionic concentration (associated with the electrolyte) changes on the interface as target binding increases (Berggren et al., 2001; Berney, 2004; Santos et al., 2014b). Interfacial capacitance in such assays is modeled as a parallel-plate contained in an equivalent circuit model of the interface, where the electrolyte resistance appears in series with this interfacial capacitance (Berggren et al., 2001). It is worth noting that while the faradaic approach has disadvantages based on the needs of pre-doping the solution with a redox probe, the nonfaradaic approach shows some disadvantages/issues related to receptor surface design (Berggren et al., 2001) and usually suffers from lack of selectivity (Daniels and Pourmand, 2007) and sensitivity.

As an alternative to both the approaches mentioned, redox capacitive assays combine high sensitivity and the lack of need for pre-doping the solution with a redox probe. In redox capacitive assays the probe is responsible for generating a sensitive electrochemical signal which is already (previously added) contained in the receptive interface; however, instead of using the charge transfer resistive signal, a useful transducer electrochemical signal is associated with the redox capacitance (a kind of faradaic capacitive signal, $C_{r}$ ) (Fernandes et al., 2013; Fernandes et al., 2014; Lehr et al., 2014). This capacitance can sometimes be (depending on the project of redox self-assembly monolayer designing) one or two orders of magnitude higher than those associated with nonfaradaic capacitive events (Fernandes et al., 2014; Marques et al., 2015; Santos et al., 2015b). Redox (or electrochemical) capacitance is a measure of electrochemical density of the states of a redox active monolayer which was demonstrated to be highly sensitive to binding events (antigen-antibody coupling) (Fernandes et al., 2013; Fernandes et al., 2014; Lehr et al., 2014), and to changes in environmental dielectrics (Bueno and Davis, 2014a). However, as already mentioned it is not associated with non-faradaic doublelayer capacitive effects (it exists additionally to double-layer effects and can sometimes dominate the capacitive signal) (Fernandes et al., 2014; Marques et al., 2015).

In spite of a considerable number of impedance bioassays reported in literature for either cancer detection (specially glycoproteins or cancer cells) (Bertok et al., 2013a, 2013b; Hu et al., 2013) or biological affinity studies (lectin-glycoprotein and lectincell binding) (Carvalho et al., 2014; Santos et al., 2014a), there are only few studies which do not require the modeling of interface with an equivalent circuit (Bedatty Fernandes et al., 2015; Patil et al., 2015). These applications are supported by the use of immittance function approaches ( $I m F s$ ) (Bedatty Fernandes et al., 2015; Patil et al., 2015) or the use of redox capacitance signals obtained directly from Nyquist or Bode capacitive diagrams (Santos et al., 2014a; Marques et al., 2015). Accordingly, the main goal of the present work is to extend the use of ImFs beyond those associated with antigen-antibody bioassays (Bedatty Fernandes et al., 2015; Patil et al., 2015) to glycoprotein-lectins. Concomitantly using the Langmuir isotherm adsorption model and the ImFs approach, it is thus demonstrated here that it is possible either to detect and/or quantify the binding affinity of glycoproteinslectins systems. More details on the Langmuir isotherm approach will be described in the results and discussion section.

Regarding the immittance functions approach, it can be shortly 
said that it is comprised of the possibility of assessing a library of different complex functions $\left(Z^{*}, Y^{*}, M^{*}\right.$, and $C^{*}$, i.e. complex impedance, admittance, modulus, and capacitance). These complex functions contain their imaginary and real components that can also be applied as transduction signals and their empirical (or pure electroanalytical) use is possible without considering any interfacial (circuit or physical chemistry) model (Bedatty Fernandes et al., 2015; Patil et al., 2015). For instance, a given set of impedance raw data as the fingerprint of an interfacial sensing process generate immittance function parameters that respond quite sensitively but differently for the same interface (Bedatty Fernandes et al., 2015; Patil et al., 2015). Since ImFs are mathematically related (Bedatty Fernandes et al., 2015; Patil et al., 2015), the associated approach consists of collecting frequency-dependent impedance data at a given DC electrochemical potential and convert them (using appropriate home-made mathematical software) into related immittance-target functions, thus generating a library of accessible and analytically useful immittance functions, $\operatorname{ImF}(\omega)$, as well as their associated parameters, as detailed in the experimental section. Obviously, each $\operatorname{ImF}(\omega)$ can be evaluated at different target concentrations and thus analytical curves (for specifically chosen or all frequencies) can be constructed and analyzed. The potential of creating a library of $\operatorname{ImF}(\omega)$ is based in the fact that some functions are more sensitive than others for the same interfacial changes (due the target-receptor interaction) in a correspondent chosen frequency (Patil et al., 2015). Consequently, a specific frequency (or preferably a range of frequencies, typically from 100 to $1.0 \mathrm{~Hz}$, as will be demonstrated) can be used in analytical procedures, thus reducing the acquisition-time ( $<3 \mathrm{~min}$ ) with optimized sensitivities and automatized/optimized limit of detection (LOD) (Patil et al., 2015).

Specifically we reinforce that we use the immittance function concept here for both detecting and quantifying the lectin-glycoprotein binding affinity. As a biochemical interaction model, we constructed a label-free ArtinM based bioassay receptive interface containing a tethered redox probe self-assembled monolayer. The priority was to detect HRP glycoprotein (horseradish peroxidase), a high-mannose content glycoprotein (Straus, 1981), by using the electrochemical activity associated with redox centers to amplify the signal. ArtinM was preferable as the lectin model due to its importance, being a non-glycosylated tetrameric lectin (a carbohydrate binding protein) composed of identical $16-\mathrm{kDa}$ protomers which exhibit a high specificity for mannose in N-glycans (Rosa et al., 1999; Nakamura-Tsuruta et al., 2008) presented in the cell membranes (Pereira-Da-Silva et al., 2012). It is also well known that the lectin ArtinM is involved in cell death of NB4 promyelocytic acute leukemia cells through recognition of aberrant glycosylation ( $\beta 1,6-G l c N A c$ branched $\mathrm{N}$-glycans) on the cell membrane (Carvalho et al., 2011), demonstrating feasibility for important clinical applications.

In summary, in this work we derivate, concomitantly considering Langmuir isotherm assumptions, mathematic relations between the $\operatorname{ImFs}$ (as transduction signal) and target concentrations, which enable us to calculate the affinity constant $\left(K_{a}\right)$ of the biorecognition of HRP-ArtinM in an optimized manner, leading to the highest sensitivity possible. From all ImFs studied in this work, it was possible to obtain sensitive assays within pico to nanomolar limits of detection (LOD) and equivalent $K_{a}$ values (as physical and chemically expected), clearly highlighting the promise of the ImFs approach in glycoprotein detection (including glycoarrays future developments) and quantitative multiplexable bio-interaction evaluation.

\section{Experimental section}

\subsection{Chemicals and biochemical reagents}

All reagents described in this section were purchased from Sigma-Aldrich except the lectin ArtinM, which was extracted from Artocarpus heterophyllus seeds by affinity chromatography with immobilized D-mannose (Santos-De-Oliveira et al., 1994).

Solutions of ArtinM $\left(0.15 \mathrm{mg} \mathrm{mL}^{-1}\right)$, gelatin $(0.1 \%, \mathrm{~m} / \mathrm{v})$, and bovine serum albumin (BSA) $0.1 \%(\mathrm{~m} / \mathrm{v})$ were prepared in phosphate buffered saline (PBS), $\mathrm{pH} 7.4$, with the composition: $\mathrm{NaCl}$, $137 \mathrm{mmol} \mathrm{L}^{-1} ; \mathrm{KCl}, 2.7 \mathrm{mmol} \mathrm{L}^{-1} ; \mathrm{Na}_{2} \mathrm{HPO}_{4} \cdot 12 \mathrm{H}_{2} \mathrm{O}, 10 \mathrm{mmol} \mathrm{L}^{-1}$; $\mathrm{KH}_{2} \mathrm{PO}_{4}, 1.8 \mathrm{mmol} \mathrm{L}^{-1}$. Solutions of $\mathrm{PBS}, 500 \mathrm{mmol} \mathrm{L}^{-1} \mathrm{NaOH}$, $500 \mathrm{mmol} \mathrm{L}^{-1} \mathrm{KOH}$, and $500 \mathrm{mmol} \mathrm{L}^{-1} \mathrm{H}_{2} \mathrm{SO}_{4}$ were prepared in Milli-Q water (Simplicity UV ultrapure water system from Millipore with $18.2 \mathrm{M} \Omega \mathrm{cm}$ at $25^{\circ} \mathrm{C}$ ). The mixtures of 16-mercaptohexadecanoic acid (16-MHDA) $0.2 \mathrm{mmol} \mathrm{L}^{-1}$ and 11-(ferrocenyl)undecanethiol (11-Fc) $2 \mathrm{mmol} \mathrm{L}^{-1}$ were prepared in anhydrous ethanol. Mixtures of $200 \mathrm{mmol} \mathrm{L}^{-1} \mathrm{~N}$-(3-dimethylaminopropyl)- $\mathrm{N}$ '-ethylcarbodiimide (EDC) and $50 \mathrm{mmol} \mathrm{L}^{-1} \mathrm{~N}$-hydroxysuccinimide (NHS) were prepared in Milli-Q water. Supporting electrolyte solution of $20 \mathrm{mmol} \mathrm{L}^{-1}$ tetrabutylammonium perchlorate $\left(\mathrm{TBA}-\mathrm{ClO}_{4}\right)$ for electrochemical measurements was prepared in a mixture of acetonitrile: Milli-Q water $(20 / 80, v / v)$.

\subsection{Electrochemical measurements}

All experiments were performed at room temperature $\left(25^{\circ} \mathrm{C}\right)$ using $\mathrm{TBA}^{-\mathrm{ClO}_{4}}$ solution. Cyclic voltammetry (CV) and electrochemical impedance spectroscopy (EIS) measurements were performed using an AUTOLAB potentiostat, model PGSTAT302N, equipped with a frequency response analysis (FRA) module, and the NOVA software from Metrohm. A three-electrode system was used, including the gold electrode as the working electrode $(2 \mathrm{~mm}$ diameter), a platinum mesh as the counter electrode and a homemade $\mathrm{Ag} / \mathrm{AgCl}$, saturated with $\mathrm{KCl}$ solution as the reference electrode. All potentials referred to in this work are relative to $\mathrm{Ag}$ / $\mathrm{AgCl}$, (saturated $\mathrm{KCl}$ ).

\subsection{Surface engineering}

Firstly, gold electrodes were mechanically polished with 1.0, 0.3 , and $0.05 \mu \mathrm{m}$ grain-sized aluminum oxide aqueous suspensions (Buehler) followed by sonication in deionized water for $5 \mathrm{~min}$ to remove adherent particles. CVs for the electrochemical desorption step were performed in $500 \mathrm{mmol} \mathrm{L}^{-1} \mathrm{NaOH}$, from -1.7 to $-0.7 \mathrm{~V}, 300$ cycles, at a scan rate of $100 \mathrm{mV} \mathrm{s}^{-1}$. After this, the electrodes were immersed in stirred anhydrous ethanol for $20 \mathrm{~min}$ to reduce gold oxide (Tkac and Davis, 2008). Finally, a CV electrochemical cleaning step was performed in $500 \mathrm{mmol} \mathrm{L}^{-1} \mathrm{H}_{2} \mathrm{SO}_{4}$ from -0.2 to $1.5 \mathrm{~V}, 25$ cycles, at a scan rate of $100 \mathrm{mV} \mathrm{s}^{-1}$, followed by $\mathrm{CV}$ gold oxide stripping in $\mathrm{H}_{2} \mathrm{SO}_{4} 500 \mathrm{mmol} \mathrm{L}^{-1}$ from 0.7 to $0.2 \mathrm{~V}, 10$ cycles, at a scan rate of $100 \mathrm{mV} \mathrm{s}^{-1}$. Electroactive areas were calculated based on the cyclic voltammograms from the electrochemical cleaning step by integrating the cathodic peak on the last scan (25th cycle) using a value of $482 \mu \mathrm{C} \mathrm{cm}^{-2}$ (Goes et al., 2012; Marques et al., 2015). These determinations $\left(0.036 \pm 0.002 \mathrm{~cm}^{2}\right)$ were used to normalize the electrochemical immittance functions.

As described previously, the ArtinM immobilization strategy was based on a bifunctional self-assembled monolayer (SAM) (Santos et al., 2014a) consisting of a spacer tethered redox probe thiol for signal transduction $(11-\mathrm{Fc})$ and a carboxylic end group thiol (16-MHDA) for lectin attachment. Using this approach, predoping of the analytical solution with a redox probe for electrochemical signal analysis and measurements is not necessary. The 

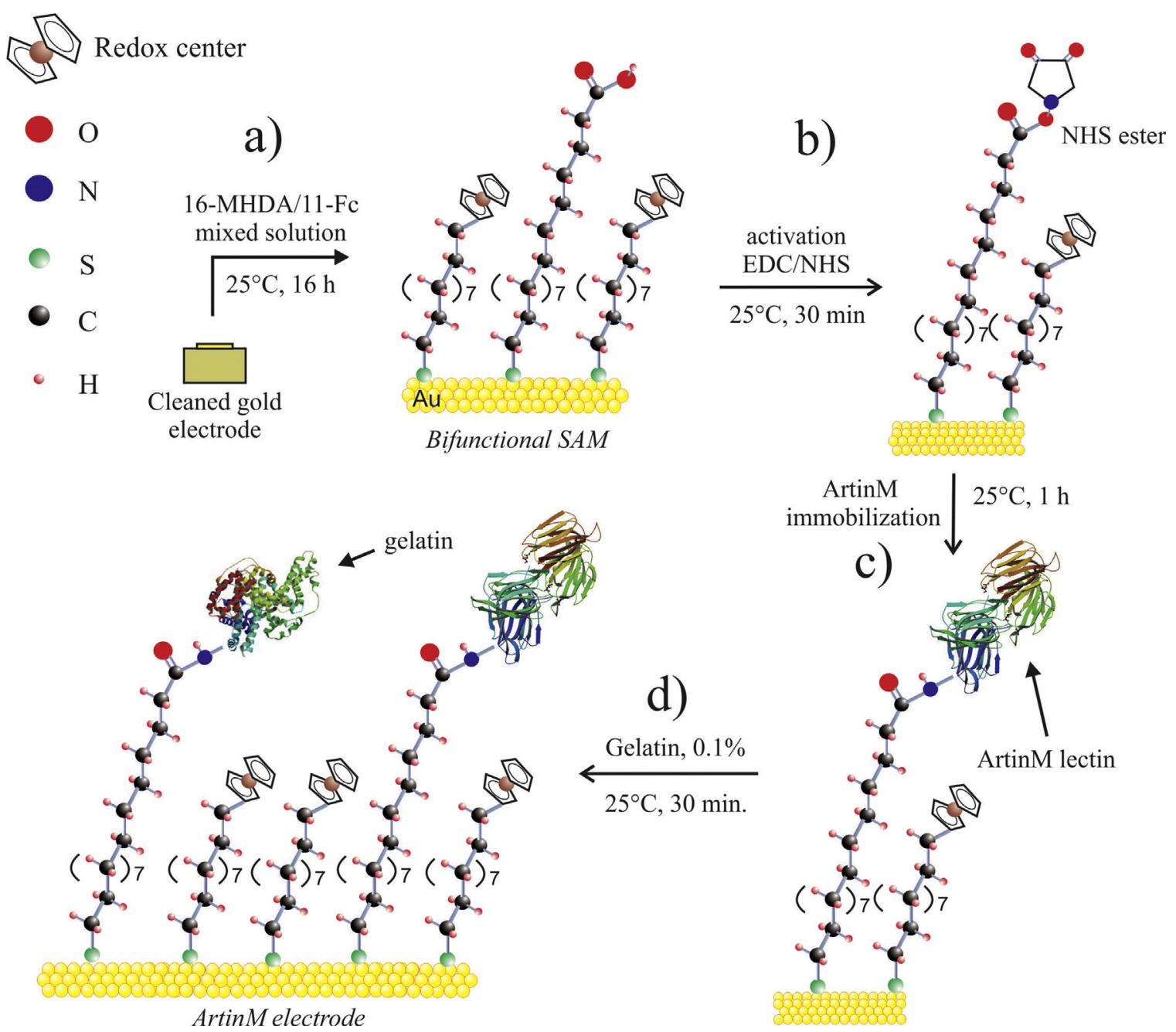

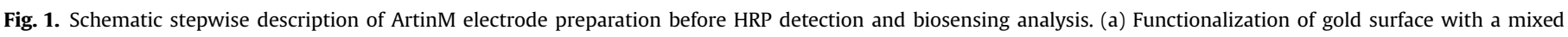

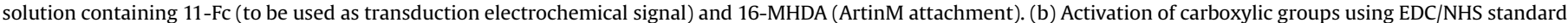

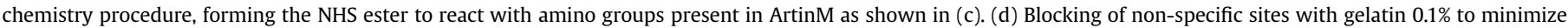
interference (molecules not drawn to scale).

electroactive bifunctional SAMs were constructed by immersing a cleaned gold electrode in a mixture of $0.2 \mathrm{mmol} \mathrm{L}^{-1} 16-\mathrm{MHDA}$ and $2.0 \mathrm{mmol} \mathrm{L}-111-\mathrm{Fc}$ in ethanol for $16 \mathrm{~h}$ at $25^{\circ} \mathrm{C}$. The carboxyl groups of 16-MHDA were activated with an aqueous solution containing $0.4 \mathrm{~mol} \mathrm{~L}^{-1} \mathrm{EDC}$ and $0.1 \mathrm{~mol} \mathrm{~L}^{-1} \mathrm{NHS}$ for $30 \mathrm{~min}$ in order to obtain NHS ester. Subsequently, the electrode was washed in PBS, dried with nitrogen gas, and immersed in $0.15 \mathrm{mg} \mathrm{mL}^{-1}$ ArtinM solution for $1 \mathrm{~h}$. Finally, the ArtinM electrodes were immersed in a $0.1 \%$ gelatin solution for 30 min to block unspecific sites (Fig. 1).

It must be stressed that it was not used any substrate (such as hydrogen peroxide) that could provoke HRP parallel enzymatic redox catalytic signal and thus interference during impedance analysis. Consequently, the HRP redox activity is absent in our experiments and does not interfere with that electrochemical signal of the tethered redox couple. Indeed, previously investigation of $\mathrm{H}_{2} \mathrm{O}_{2}$ enzymatic reaction catalyzed by HRP immobilized interface demonstrates and confirms this statement (Pesquero et al., 2010).

Impedance analysis and cyclic voltammetry measurements were taken after each step of the bioassay interface design to confirm an appropriate receptive surface construction. After SAM formation, $\mathrm{CV}$ was performed from 0.0 to $0.7 \mathrm{~V}$ in three cycles at a scan rate of $100 \mathrm{mV} \mathrm{s}^{-1}$ to obtain the redox-in potential
$E_{i n}=\left(E_{o x}+E_{\text {red }}\right) / 2$, where $E_{o x}$ and $E_{\text {red }}$ are the oxidation and reduction peak potentials, respectively. Impedance analyses were performed at $E_{i n}$ in a frequency range of $0.01-100,000 \mathrm{~Hz}$ (60 frequencies logarithmically arranged), peak-to-peak amplitude of $10 \mathrm{mV}$, $0.125 \mathrm{~s}$ of maximum integration time and one cycle as minimum number of cycles to integrate.

$\mathrm{CV}$ electrochemical desorption step was performed in $500 \mathrm{mmol} \mathrm{L}^{-1} \mathrm{KOH}$ with potential ranging from -0.8 to $-1.4 \mathrm{~V}$, 15 cycles at a scan rate of $100 \mathrm{mV} \mathrm{s}^{-1}$ to obtain the bi-functional SAM surface coverage $\left(\Gamma_{\text {SAM }}\right)$. 11-Fc surface coverage $\left(\Gamma_{11-\mathrm{Fc}}\right)$ was estimated by anodic peak integration of the CV as described in more detail previously (Marques et al., 2015).

\subsection{Assessment of ArtinM-HRP interaction and HRP detection by immittance functions}

After receptive and redox active surface construction, and its characterization by CV and EIS, the ArtinM functional electrodes were exposed for $30 \mathrm{~min}$ to eight different concentrations of the HRP glycoprotein, ranging from 0.5 to $100 \mathrm{nmol} \mathrm{L}^{-1}$ prepared in PBS solution. After exposure to each HRP concentration, the electrodes were washed in PBS and impedance analysis was carriedout at $E_{\text {in }}$ using $\mathrm{TBA}^{-\mathrm{ClO}_{4}}$ as the supporting electrolyte, wherein modulation frequency varied in 60 steps (frequency range of $0.01-$ 
a)

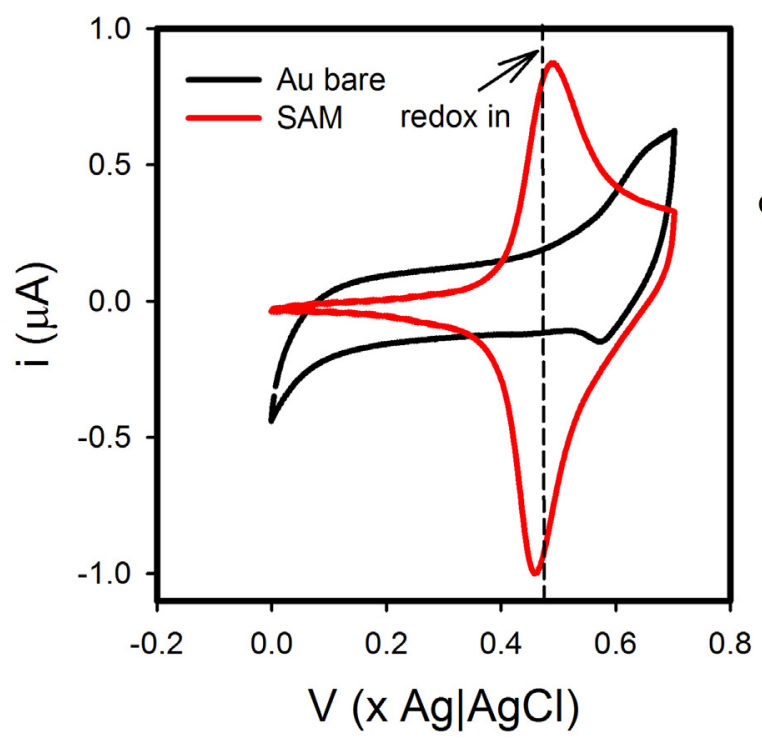

b)

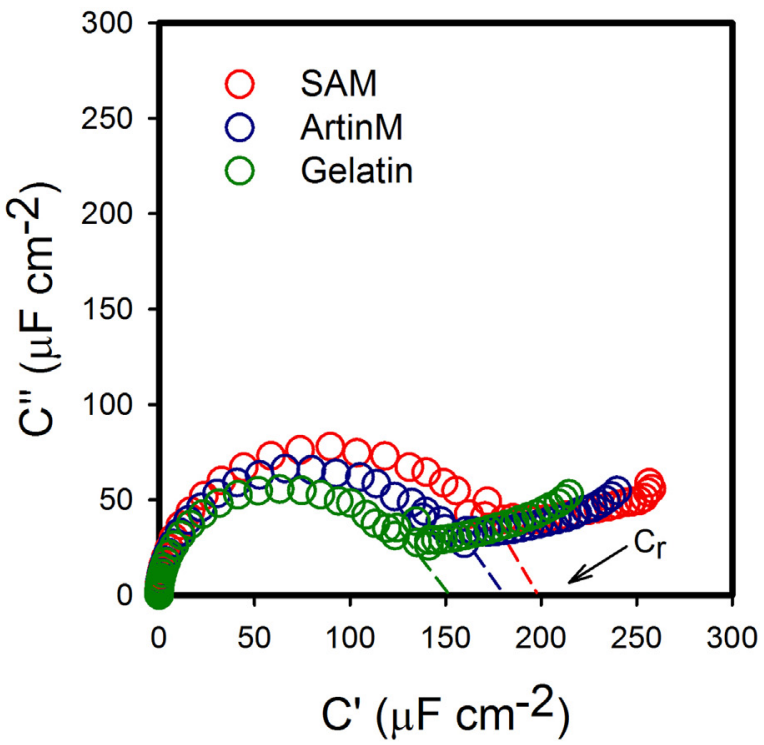

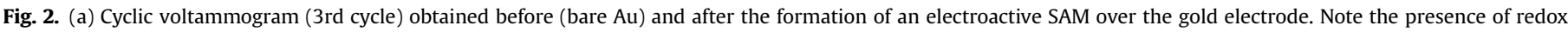

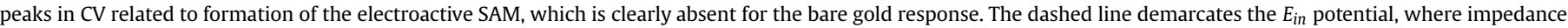

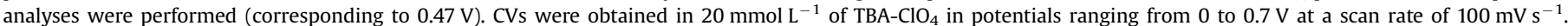

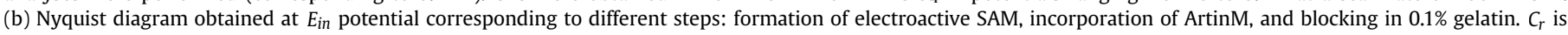
easily obtained from the diameter semicircle for each step (Marques et al., 2015), as shown in the Nyquist capacitive diagram.

$100,000 \mathrm{~Hz}$ ), with peak-to-peak amplitude of $10 \mathrm{mV}$. A typical acquisition of impedance data over the full frequency range (as described in Section 2.3), considering the incubation time, is approximately $50 \mathrm{~min}$. Consequently, acquisition of eight-point calibration curve, including blank measurement, requires approximately $7.5 \mathrm{~h}$ for a full analytical curve. All the assays were performed in triplicate (three different electrodes).

The analytical complex immittance functions $\left(I m F s^{*}\right)$ used in this work were impedance $\left(Z^{*}\right)$, admittance $\left(Y^{*}\right)$, capacitance $\left(C^{*}\right)$ and modulus $\left(M^{*}\right)$. Their phasorial relationships are, in considering impedance complex $\left(Z^{*}(\omega)=Z^{\prime}+j Z^{\prime \prime}\right)$ (Patil et al., 2015):

$C^{*}=1 / j \omega Z^{*}$

$Y^{*}=j \omega C^{*}=1 / Z^{*}$

$M^{*}=j \omega Z^{*}$

where $j=\sqrt{-1}$ and $\omega=2 \pi f$.

As can be observed, all complex immittance functions are related to impedance $\left(Z^{*}\right)$ and since they have modulus ( $\left.|I m F s|\right)$, real $\left(I m F s^{\prime}\right)$, and imaginary parts $\left(I m F s^{\prime \prime}\right)$, it constitutes 12 different parameters for any sample frequency. In this work, in addition to these functions, six more parameters were added, based on the relationship between imaginary and real parts of ImFs and the inverse of both real and imaginary parts of capacitance $\left(Z^{\prime \prime}\left|Z^{\prime}, C^{\prime \prime}\right| C^{\prime}\right.$, $Y^{\prime \prime} / Y^{\prime}, M^{\prime \prime} / M^{\prime}, 1 / C^{\prime}$ and $\left.1 / C^{\prime \prime}\right)$. Consequently, there were 18 different parameters overall as the analytical signal for each frequency for different HRP concentrations.

The response $(R)$ obtained for each parameter was evaluated across a frequency range as the target concentration (HRP) was varied. In order to normalize the transduction signal for each $\operatorname{ImF}$ the relative response was used. The relative response $(R R)$, for each HRP concentration in a certain frequency $(f)$, was, for all $I m F s$, defined as:
$R R_{[H R P]}^{f}(\%)=\left[\left(R_{[H R P]}^{f}-R_{0}^{f}\right) / R_{0}^{f}\right] \times 100$

where $R_{0}^{f}$ represents the initial value of $\operatorname{ImF}$ in the absence of analyte (blank measurement) and $R_{[H R P]}^{f}$ is the value of $\operatorname{Im} F$ after exposure of the ArtinM functionalized electrode to the corresponding HRP concentration at the same frequency $f$. Collecting $R R$ over a range of target concentrations, it was possible to plot $n$ analytical curves for each $\operatorname{ImF}$, wherein $n$ represents the number of frequencies used in the assay. The optimal frequency corresponds to the analytical curve which has a higher (in modulus) correlation coefficient (Pearson, $r_{x y}$ ), higher determination coefficient $\left(R^{2}\right)$, higher sensitivity (angular coefficient), lowest limit of detection (LOD, defined as $3.3 \times \mathrm{SD}$, where SD means standard deviation of the blank (Long and Winefordner, 1983)), and lowest relative standard deviation (RSD). In this work, the optimized frequencies for each parameter were reported from those corresponding to $\left|\mathrm{r}_{\mathrm{xy}}\right|>0.97, \mathrm{R}^{2}>0.95$ and $\mathrm{RSD}<18 \%$. In order to evaluate nonspecific interaction, BSA (a non-glycosylated protein) was used at $100 \mathrm{nmol} \mathrm{L}^{-1}$.

\section{Results and discussion}

\subsection{Design of the bioassay interface}

Despite the facility to construct functionalized SAMs on gold surfaces, several studies have demonstrated the importance of the pre-cleaning protocol to assure reproducibility and appropriate density packing of these monolayers (Tkac and Davis, 2008). In this work, chemical reduction (in basic media), mechanical, electrochemical polishing, and electrochemical gold oxide stripping were combined as suggested by Tkac and Davis (2008). Using this protocol, the bifunctional SAM (with redox and glycoprotein receptive function) presented a surface coverage of $(5 \pm 1) \times 10^{-10} \mathrm{~mol} \mathrm{~cm}^{-2}$, a value in the same order of magnitude as that of alkanethiol SAMs $\left(7.5 \times 10^{-10} \mathrm{~mol} \mathrm{~cm}^{-2}\right)$ (Love et al., 
$2005)$. The $11-\mathrm{Fc}$ surface coverage $\left(\Gamma_{11-\mathrm{Fc}}\right)$ estimated by using the anodic peak of the CV (SAM in Fig. 2a) was of $(2.5 \pm 0.3) \times 10^{-10} \mathrm{~mol} \mathrm{~cm}^{-2}$ (more details are given in Supplementary Material). Both values correlate with those obtained in a previous study using the same bi-functionalized SAM (Marques et al., 2015).

The SAM functionalization step was evaluated by CV and EIS, with the latter converted to complex capacitance (Eq. (1)). From the Nyquist complex capacitance diagrams it was possible to obtain/access the redox capacitance signal $\left(C_{r}\right)$, which is related to the ability of the redox SAM in storage energy when a certain electrical potential is applied and the redox centers are proportionally occupied (Bueno et al., 2012; Bueno and Davis, 2014b; Santos et al., 2014b; Bueno et al., 2015). The $C_{r}$ signal is sensitive to environmental changes caused by antibody-antigen interaction on the interface (Fernandes et al., 2013, 2014; Lehr et al., 2014; Marques et al., 2015; Santos et al., 2015b). As mentioned previously, this can alternatively be used as the transduction signal for glycoprotein binding on interfaces containing ArtinM as the receptive centers. The binding event usually represents a decrease in $C_{r}$ signal (Fernandes et al., 2014; Santos et al., 2014a, 2014b; Marques et al., 2015, Santos et al., 2015b). More details regarding equivalent circuit modeling of electrochemical capacitive interfaces comprising of redox electroactive films are provided in literature (Fernandes et al., 2014; Lehr et al., 2014; Marques et al., 2015).

As depicted in Fig. 2a, CV responses obtained before SAM formation over the gold surface does not show any redox activity (any redox peaks are identified) as expected. However, when SAM is formed (chemically or covalently attached) on the gold electrode, two clear peaks are evidenced on CV response, exhibiting a reversible redox process with the anodic and cathodic current peak approaching the unit $\left(i p_{a} / i p_{c} \sim 1\right)$ and with a very small potential difference between these peaks, $\sim 30 \mathrm{mV}$. The vertical line in Fig. 2a demarcates the redox-in potential $\left(E_{\text {in }} \sim 0.47 \mathrm{~V}\right)$ which corresponds to the formal potential of this highly reversible electrochemical process. This redox-in potential is very useful since it is the potential in which the maximum redox capacitive activity is achieved. Fig. 2b shows the Nyquist capacitive plots obtained at $E_{\text {in }}$ for each step of construction of the redox active and glycoprotein bio-receptive interfaces. At $E_{\text {in }}$ it can be seen that the electroactive SAM, without bio-receptive centers, exhibits a $C_{r}$ value of $\sim 200 \mu$ $\mathrm{F} \mathrm{cm}^{-2}$. After ArtinM is attached or immobilized on the interface, the redox capacitance decreased to $C_{r} \sim 178 \mu \mathrm{F} \mathrm{cm}^{-2}$ which indicates environmental perturbation around ferrocenyl groups due to lectin attachment/binding to this interface. Subsequently gelatin was added to block the remaining non-specific sites and as expected an additional decrease was observed $C_{r} \sim 150 \mu \mathrm{F} \mathrm{cm}^{-2}$ Altogether, these results demonstrate proper electrode modification (or construction of the appropriate receptive interface) for detection of HRP as the target glycoprotein.

\subsection{Glycoprotein detection, analytical curves, and sensitivity}

Redox tagged and either ArtinM functionalized electrodes, prepared as described in the previous section, were exposed for 30 min to different HRP concentrations (0.5, 1.0, 5.0, 10.0, 25.0, 50.0, 75.0, $100.0 \mathrm{nmol} \mathrm{L}^{-1}$ ) in PBS ( $\mathrm{pH} \mathrm{7.4).} \mathrm{After} \mathrm{this,} \mathrm{the} \mathrm{elec-}$ trodes were washed with PBS and impedance analysis were performed (in the supporting electrolyte solution containing

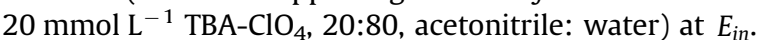

The principle of ImFs electroanalysis is based on measuring the impedance spectrum to obtain its real $\left(Z^{\prime}\right)$ and imaginary $\left(Z^{\prime \prime}\right)$ components, obviously at different frequencies. After this, using mathematically defined immittance functions (Eqs. (1)-(3)), the real $\left(I m F s^{\prime}\right)$, imaginary $\left(I m F s^{\prime \prime}\right)$, and the modulus (IImF|) of all $I m F s$ can be obtained. By adding the ratios (imaginary component divided by its real part) and the inverse of imaginary and real parts of capacitance, it was herein possible to obtain 18 analytical parameters that could be used to construct analytical curves by measuring the impedance spectrum of the interface chemically incubated at different target concentrations, as detailed in the experimental section.

The advantages of using ImFs as the electroanalytical transduction signal in clinical or bioassays is sustained on the capability of optimizing the frequency for each $\operatorname{ImF}$, which corresponds to accomplishing the most sensitive transduction signal with the lowest LODs possible (usually it has been achieved pico to nanomolar range). Thus reproducibility and the fastest assays (corresponded to highest frequency) (Patil et al., 2015) are obtained for a given impedance (or electrical transfer function) spectrum.

In order to compare all ImFs, the relative response $(R R)$ which, essentially, consists in measuring changes (in percentage) in $\operatorname{Im} F$ signal obtained for certain HRP concentration in comparison with the blank signal, was used (Eq. (4)). Once all $\operatorname{ImF}$ parameters can be used as the transduction signal and are obtained over a frequency range (Fig. 3), it is easy to determine the optimal frequency (or frequency range) where sensitivity is maximized and the linear regression presents $R^{2}>0.95,\left|r_{x y}\right|>0.97$ (strong linear relationship) and RSD $<18 \%$.

For example, while analyzing the $R R$ signal for $1 / C^{\prime \prime}$ parameter (Fig. 4) it is possible to verify that the optimized frequency range response is between 0.1 and $20 \mathrm{~Hz}$ (hachured area). By converting impedance raw data spectrum in all 18 analytical parameters, it is possible to verify the optimized frequency for each parameter used for signal transduction (as summarized in Table 1). All analytical curves are shown in Fig. 3S in Supplementary Material. HRP detection and sensitivity the $1 / \mathrm{C}^{\prime \prime}$ parameter at $7.04 \mathrm{~Hz}$ represents the most sensitive frequency (a sensitivity of $37 \%$ per decade of HRP concentration) with a LOD of $0.4 \mathrm{nmol} \mathrm{L}^{-1}$, a value in the same order of magnitude as that obtained by the redox capacitive approach $\left(0.2 \mathrm{nmol} \mathrm{L}^{-1}\right)$. In contrast, in analyzing the real part of admittance $\left(Y^{\prime}\right)$, a lower LOD of $0.06 \mathrm{nmol} \mathrm{L}^{-1}$ at a higher frequency $(9.24 \mathrm{~Hz})$ is obtained. Notably, all parameters are unresponsive to BSA, a non-glycosylated protein used here as the negative control (see Fig. 4S in Supplementary Material), demonstrating the selectivity of this assay methodology independently of any elected parameter.

Since the redox capacitance signal is spectroscopically (through capacitance spectroscopy analysis) assessed at low frequencies (Bueno and Davis, 2014b), it is clear that the signal of $1 / C^{\prime}$ approaches that obtained directly by extracting the redox capacitance signal $\left(1 / C_{r}\right)$, at low frequencies. Indeed, $1 / C^{\prime}$ signal presented similar value for LOD $\left(\sim 0.30 \mathrm{nmol} \mathrm{L}^{-1}\right)$ at $0.6 \mathrm{~Hz}$ either with a similar sensitivity of $23 \%$ decade $^{-1}$ when compared with values obtained by $1 / C_{r}$. This not only validates the proposed methodology but also demonstrates its consistency. Nonetheless, the time required (to construct an analytical curve with eight concentration points) in a complete analysis by using redox capacitance methodology, considering a frequency range from $100,000 \mathrm{~Hz}$ to $0.01 \mathrm{~Hz}$ (60 frequencies) and an incubation time of $30 \mathrm{~min}$, is about $7.5 \mathrm{~h}$ (details in Section 2.3). On the other hand, by using $1 / C^{\prime}$ parameter at $0.6 \mathrm{~Hz}$, for example, this will take approximately $4.5 \mathrm{~h}$, which is a significant gain of time in constructing an electroanalytical calibration curve.

Interestingly, further analysis on a given set of ImFs clearly demonstrates the existence of an optimal range of frequencies where sensitivity does not change considerably. For example, the imaginary components of impedance and modulus $\left(Z^{\prime \prime}\right.$ and $\left.M^{\prime \prime}\right)$ presents a broad constant sensitivity across a frequency range of $0.15-962 \mathrm{~Hz}$ (with a sensitivity in \% decade ${ }^{-1}$ of $26 \pm 4$ ). The maximum sensitivity value is 30 at $245 \mathrm{~Hz}, \mathrm{R}^{2}=96 \%$ (Fig. 5). This 

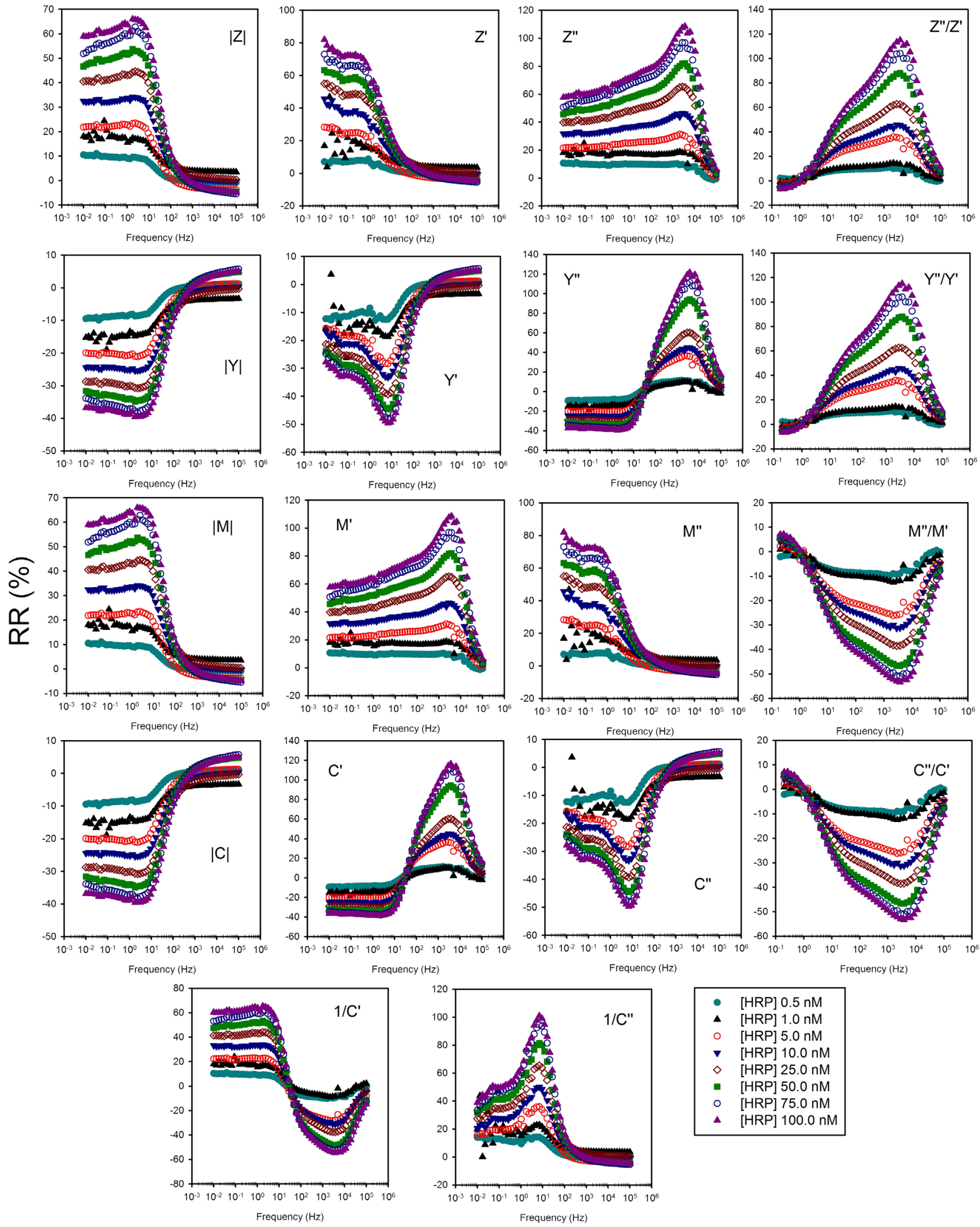

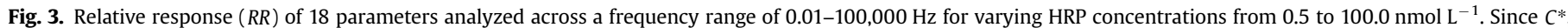
$Y^{*}$ and $M^{*}$ are phasorially derived from $Z^{*}$, several functions show a similar response (For example, compare $|Z|$ and $|M|,|C|$ and $|Y|$.

feature allows analysis of a full range of frequencies instead of a single frequency without any loss of sensitivity and yet, in this case, higher than that obtained for redox capacitance approach
( $1 / C_{r}$ signal). In addition, this optimized frequency range (from 0.15 to $962 \mathrm{~Hz}$ ) is time-advantageous when compared with a full frequency range (usually from 0.01 to $100,000 \mathrm{~Hz}$ in redox 


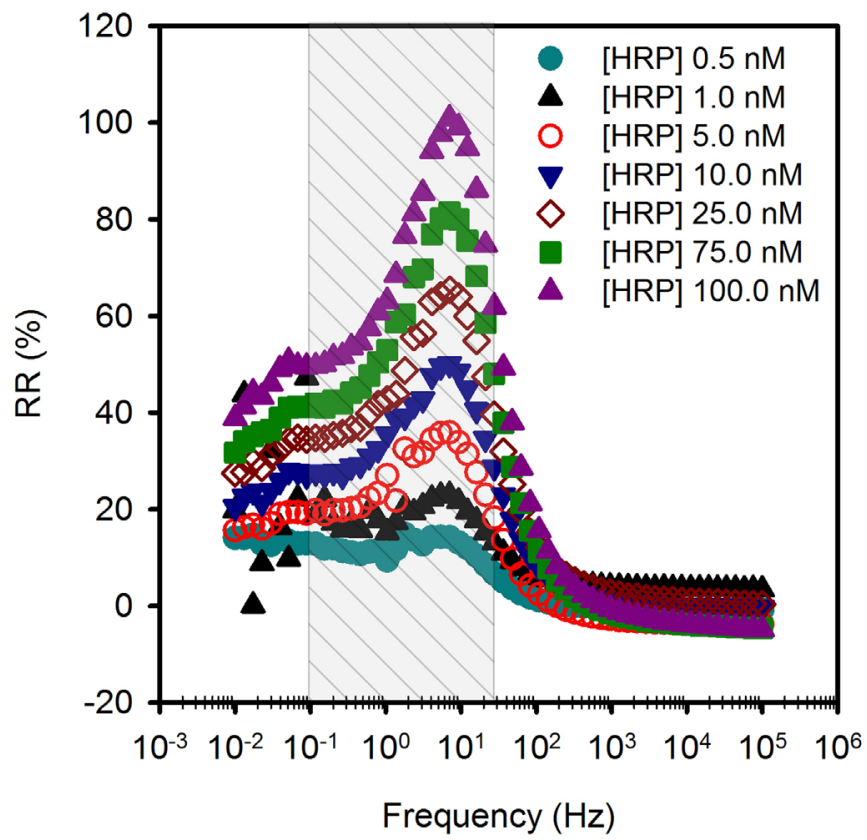

Fig. 4. $1 / C^{\prime \prime}$ response as a function of HRP concentration at the full range of frequencies. The hachured area demarcates the frequency range $(0.1-20 \mathrm{~Hz})$ corresponding to frequencies where the most sensitive analytical plots can be constructed $\left(R^{2}>95 \%\right)$.

capacitance), since in the former it necessarily takes five minutes of measurement while in the latter it generally needs about $17 \mathrm{~min}$ in a similar setup procedure.

In summary, similar to previous results and analyses performed using ImFs as transduction signal for protein target detection (Patil et al., 2015), the same methodology was successfully applied here to provide a faster yet sensitive analysis/detection for glycoproteins in comparison with redox capacitance (Santos et al., 2014a) and classical impedance measurements (Bertok et al., 2013b). In the next section, we expand the application of $\operatorname{ImFs}$ by quantifying the affinity interaction of the glycoprotein-lectin system, a biological system which is of relevant importance in some biomedical studies and applications (Mihara et al., 2010; Nelson and Cox, 2012).

\subsection{Glycoprotein-lectin binding affinity studies}

The adsorption of proteins to functionalized surfaces has received great attention (Fang et al., 2005; Chen et al., 2010; Rabe et al., 2011; Wiseman and Frank, 2012; Santos et al., 2015a) due to the possibility of quantifying bio-interaction (or bio-recognition) thus providing new insights in comprehending the role of certain proteins in biological systems (Nelson and Cox, 2012), specifically in cell-cell interactions (Ramburth and Dwek, 2011; Marchant et al., 2012; Carvalho et al., 2014). For example, lectins, a class of carbohydrate binding proteins, have been used as biorecognition elements for cancer cell detection (Ramburth and Dwek, 2011; Hu et al., 2013) which suffer some structural changes clearly as a consequence of disease onset (Reis et al., 2010; Clark and Mao, 2012). In addition, lectins are responsible for cell-cell adhesion in infectious processes and protozoan invasion (Monteiro et al., 1998; Marchant et al., 2012), and knowledge about the mechanism might help develop vaccines (Lourenço et al., 2006) and contribute to improvement of social health.

Although electrochemical methods such as electrochemical impedance spectroscopy (EIS) and electrochemical capacitance spectroscopy (ECS) have recently received special attention due their high sensitivity (Carvalho et al., 2014; Santos et al., 2014a, 2014b), they are typically long-term experiments, and especially in the faradaic impedance approach, the redox probe needs to be used as doping in the analytical solution as previously mentioned (Daniels and Pourmand, 2007; Lisdat and Schäfer, 2008). As previously discussed, in a simple impedance assay (range of frequencies from $0.01 \mathrm{~Hz}$ to $100,000 \mathrm{~Hz}, 60$ frequencies), about $17 \mathrm{~min}$ are required for each experimental point, disregarding the time for the incubation step (of about $30 \mathrm{~min}$ ). On the other hand, use of an appropriate and optimized immittance function might reduce this time to a few seconds (even less) and represents an interesting alternative for protein-protein interaction studies (Patil et al., 2015). However, until now, there are no studies regarding the use of immittance functions and their parameters to construct isotherm curves for quantifying binding affinities. It is true that faradaic impedance (through $R_{c t}$ signal) (Carvalho et al., 2014; Fernandes et al., 2014) and redox capacitance $\left(1 / C_{r}\right.$ signal) (Santos et al., 2014a) were used in the past, but due to optimization capacity of immittance functions, as observed in the previous section, we present herein an additional applicability of the

Table 1

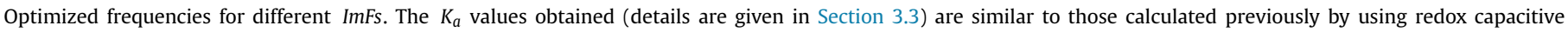
approach $(\mathrm{p}>0.09)$ considering a significance level of $5 \%$.

\begin{tabular}{|c|c|c|c|c|c|c|}
\hline $\operatorname{Im} F$ & Optimized frequency $(\mathrm{Hz})$ & $R^{2}$ & $r_{x y}$ (Pearson) & $\begin{array}{c}\text { Sensitivity } \\
\left(\% \text { decade }^{-1}\right)\end{array}$ & $\begin{array}{c}\text { LOD } \\
\left(\mathrm{nmol} \mathrm{L}^{-1}\right)\end{array}$ & $\begin{array}{c}\boldsymbol{K}_{\boldsymbol{a}} \\
\left(\boldsymbol{x} 10^{8}{\left.\mathbf{L ~} \mathbf{~ m o l}^{-1}\right)}^{-1}\right)\end{array}$ \\
\hline$|Z|$ & 2.35 & 0.96 & 0.98 & 24 & 0.30 & $1.2 \pm 0.4$ \\
\hline$Z^{\prime}$ & 0.45 & 0.96 & 0.98 & 26 & 0.40 & $1.2 \pm 0.3$ \\
\hline$Z^{\prime \prime}$ & 0.45 & 0.96 & 0.98 & 22 & 0.30 & $1.3 \pm 0.4$ \\
\hline$Z^{\prime \prime} \mid Z^{\prime}$ & 108.12 & 0.96 & 0.98 & 27 & 1.08 & $1.1 \pm 0.3$ \\
\hline$|Y|$ & 2.35 & 0.99 & -0.99 & -13 & 0.08 & $2.1 \pm 0.7$ \\
\hline$Y^{\prime}$ & 9.24 & 0.99 & -0.99 & -16 & 0.06 & $2.3 \pm 0.7$ \\
\hline$Y^{\prime \prime}$ & 0.05 & 0.99 & -0.99 & -12 & 0.06 & $2.3 \pm 0.8$ \\
\hline$Y^{\prime \prime} / Y^{\prime}$ & 108.12 & 0.96 & 0.98 & 27 & 1.08 & $1.1 \pm 0.3$ \\
\hline $\mid \mathrm{C}$ & 2.35 & 0.99 & -0.99 & -13 & 0.08 & $2.1 \pm 0.7$ \\
\hline$C^{\prime}$ & 0.05 & 0.99 & -0.99 & -12 & 0.06 & $2.3 \pm 0.8$ \\
\hline$C^{\prime \prime}$ & 9.24 & 0.99 & -0.99 & -16 & 0.06 & $2.3 \pm 0.7$ \\
\hline$C^{\prime \prime} / C^{\prime}$ & 4953 & 0.98 & -0.99 & -21 & 0.30 & $1.2 \pm 0.2$ \\
\hline $1 / C^{\prime}$ & 0.60 & 0.96 & 0.98 & 23 & 0.30 & $1.3 \pm 0.4$ \\
\hline $1 / C^{\prime \prime}$ & 7.04 & 0.96 & 0.98 & 37 & 0.40 & $1.1 \pm 0.4$ \\
\hline$|M|$ & 2.35 & 0.96 & 0.98 & 24 & 0.30 & $1.2 \pm 0.4$ \\
\hline$M^{\prime}$ & 0.45 & 0.96 & 0.98 & 22 & 0.30 & $1.3 \pm 0.4$ \\
\hline$M^{\prime \prime}$ & 0.45 & 0.96 & 0.98 & 26 & 0.40 & $1.2 \pm 0.3$ \\
\hline$M^{\prime \prime} / M^{\prime}$ & 4953 & 0.98 & -0.99 & -21 & 0.30 & $1.2 \pm 0.2$ \\
\hline $1 / C_{r}$ & - & 0.97 & 0.98 & 23 & 0.20 & $1.8 \pm 0.7$ \\
\hline
\end{tabular}



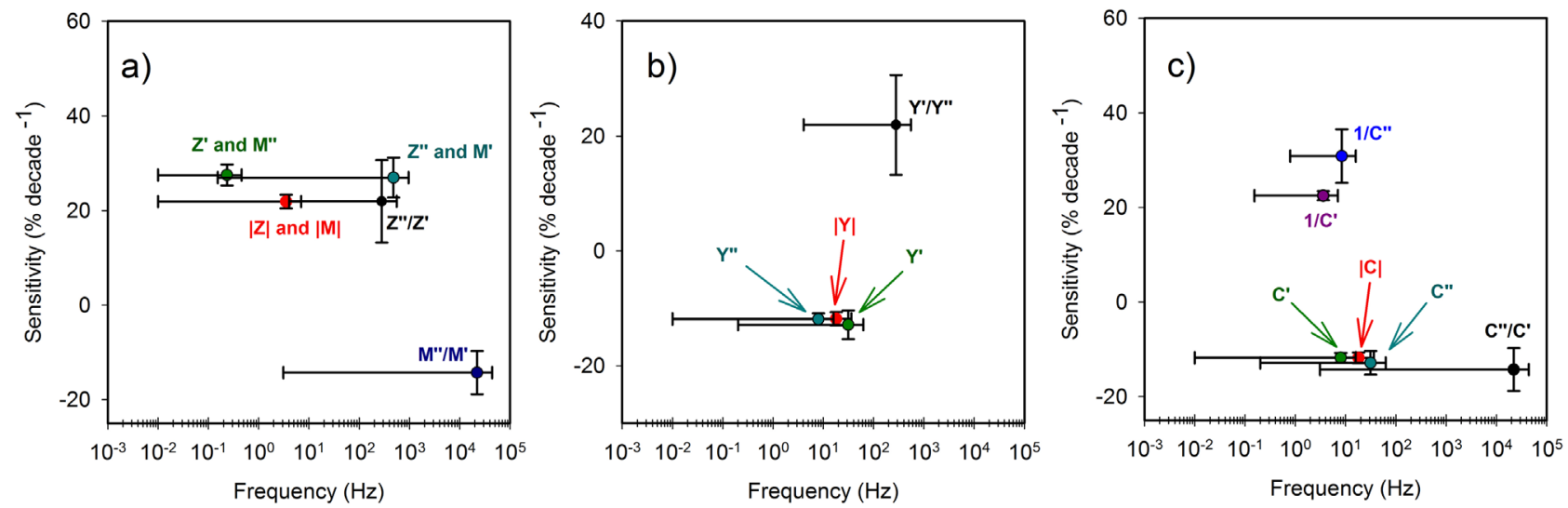

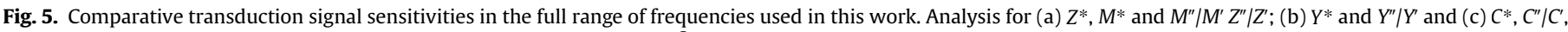
$1 / C^{\prime}$ and $1 / C^{\prime \prime}$. All sensitivities were extracted from analytical plots with $R^{2}>0.95$ in a certain frequency range.

immittance function approach related to quantification of proteinprotein (specifically glycoprotein-lectin) binding interaction in diluted conditions, i.e. clearly within the Langmuir assumptions.

The Langmuir isotherm is the most used model to understand adsorption processes between a ligand in solution and an immobilized receptor on a receptive functionalized surface (Rabe et al., 2011). This isotherm model assumes that the molecular adsorbate behaves as an ideal gas, which means that adsorbates do not interact with their neighbors in solution or in the adsorbed form. In addition, the unit occupancy of the binding sites (i.e. only one site is available per adsorbate) with equal adsorption energy in isothermal conditions is assumed (Foo and Hameed, 2010; Rabe et al., 2011). Except for the latter assumption, in dilute conditions the previously described criteria can be achieved, and this condition is the main concern in using Langmuir model for the assessment and quantification of protein-protein binding interaction. In this work, nanomolar ligand (HRP) concentrations were used to minimize adsorbate-adsorbate interaction, considering that such dilute condition is only possible due to the highly sensitivity of frequency-response techniques such as EIS, ECS, and immittance function. This assumption facilitates analysis tremendously.

Considering the Langmuir model, the dynamic equilibrium between the ligand glycoprotein $(G)$ and glycoprotein-lectin complex $(G-L)$ is described by Eq. (5) (Santos et al., 2014a):

$G+L \rightleftharpoons G-L$

The affinity constant $\left(K_{a}\right)$ for this process is given by Eq. (6):

$K_{a}=\frac{[G-L]}{[G][L]}$

where [ ] represents concentration. Assuming a surface coverage occupancy percentage given by $\theta$ and a percentage of available sites as $1-\theta$, Eq. (6) can be rewritten as

$K_{a}[G]=\frac{\theta}{1-\theta}$

Solving Eq. (7) for $\theta$, it is possible to obtain the following expression:

$\theta=\frac{K_{a}[G]}{1+K_{a}[G]}$

Since the transduction signal value $(S)$ corresponds to a certain amount of adsorbed ligand on the surface (discounting/subtracting the blank intrinsic signal), it is intrinsically proportional to the surface coverage $\left(\Gamma, \mathrm{mol} \mathrm{cm}{ }^{-2}\right)$. In assuming $S=\theta S_{m}$, where $S_{m}$ is the maximum response of adsorption, when $\theta$ approaches unity we reach Eq. (9):
$S=\frac{S_{m} K_{a}[G]}{1+K_{a}[G]}$

That can be linearized as

$\frac{[G]}{S}=\frac{[G]}{S_{m}}+\frac{1}{K_{a} S_{m}}$

Thus, the $K_{a}$ (binding affinity constant) value can be now easily obtained by the quotient between the angular $\left(1 / S_{m}\right)$ and linear $\left(1 / K_{a} S_{m}\right)$ coefficients of the linear function comprising $[G] / S$ versus $[G]$.

Interestingly, by using optimized frequencies for each immittance function, similar and characteristic saturation curves as theoretically expected for the Langmuir adsorption processes could be obtained, as exemplified in Fig. 6 for $|Z|$ at $2.35 \mathrm{~Hz}$ (more details in Fig. 5S in Supplementary Material). Indeed the transduction signal could be associated with the amount of protein adsorbed on the sensor surface and the maximum signal corresponding to the saturation value, i.e. when no considerable signal variation is observed after a given saturated concentration. Using relative response $R R$ as transduction signal (i.e. $S=R R$ ), the $K_{a}$ value for the HRP-ArtinM interaction using all immittance functions was calculated (Table 1).

As shown, all values were compared with that obtained using the redox capacitance approach [for which obtained value was $(1.8 \pm 0.7) \times 108 \mathrm{~L} \mathrm{~mol}^{-1}$, in good agreement with that previously reported, $(1.6 \pm 0.6) \times 10^{8} \mathrm{~L} \mathrm{~mol}^{-1}$ ) (Santos et al., 2014a)] and they are invariably similar ( $p>0.09, \alpha=0.05)$. This demonstrates the feasibility of this approach in obtaining $K_{a}$ values in a faster and simpler manner by the immittance function compared with processes using redox capacitance (Santos et al., 2014a) or charge transfer resistance (Carvalho et al., 2014; Fernandes et al., 2014). For example, in using $1 / C^{\prime \prime}$ parameter obtained from the complex capacitive function, the optimized frequency was $7.04 \mathrm{~Hz}$, which corresponds to a rapid measurement $(4 \mathrm{~s})$ for each point using similar setup procedure as described in Section 2.3, clearly demonstrating the viability of the approach to be applied in development of rapid and reliable glycoarrays.

\section{Final remarks and conclusions}

Glycoprotein detection is very important for clinical applications since alterations in carbohydrate structure content (aberrant glycosylation) is associated with diseases, especially neurodegenerative events and cancer. These macromolecules play important roles in biological phenomena, such as cell signaling and cell-cell interaction in invasive processes. Since lectins are carbohydrate- 

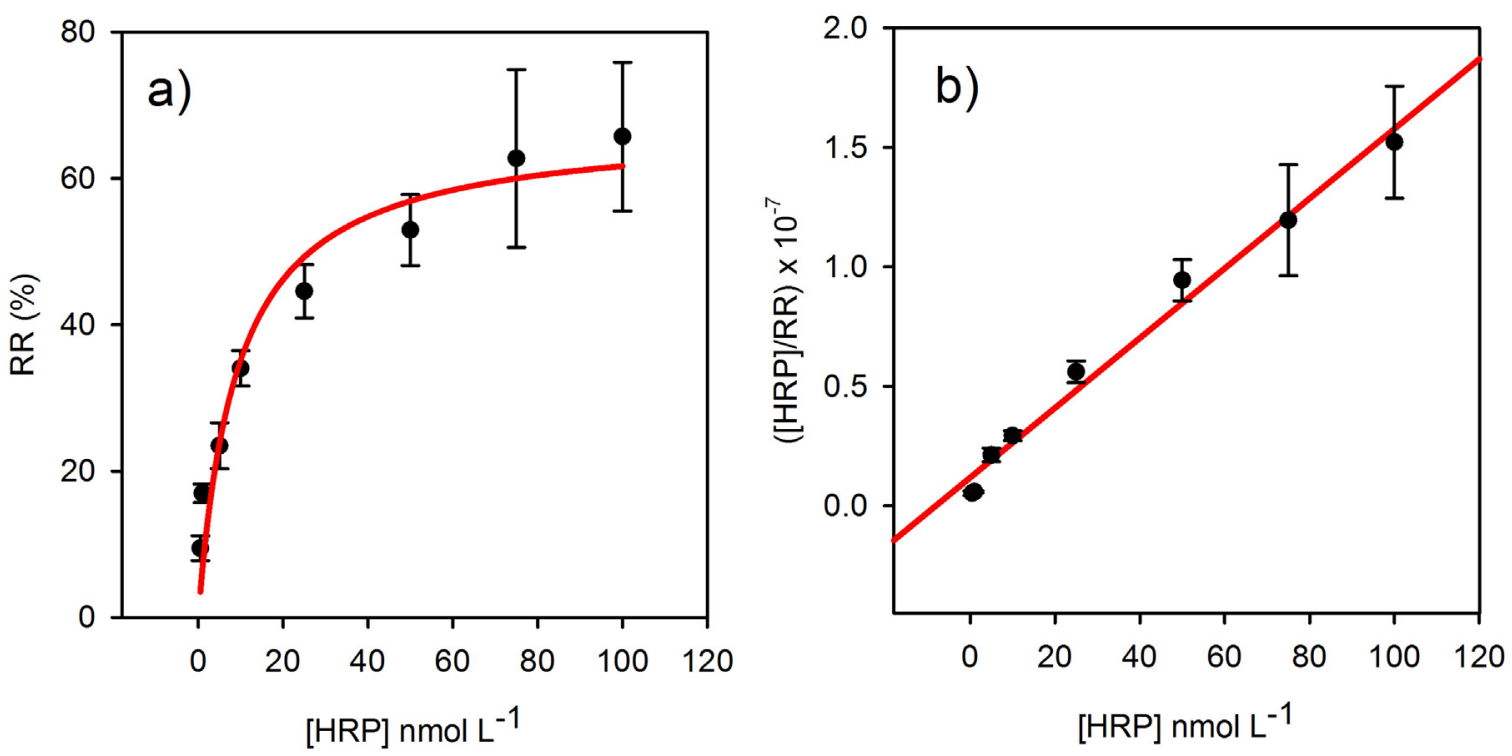

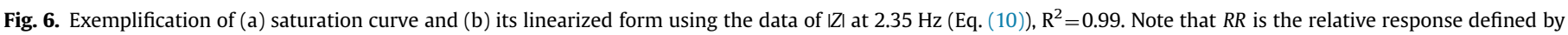
Eq. (4).

binding proteins, they can be used for both glycoprotein detection and evaluation of glycoprotein-lectin interaction. Electroanalytical techniques are a promising approach in quantification of glycoprotein-lectin interaction. Impedance assays are a promising technique among electrochemical approaches that have the sensitive and multiplexible capability to be used in the quantification of protein-protein interactions, in addition to being cost-effective and simple for automation. However, the need of collecting a full range of frequencies due to the necessary adjustment of raw data to a suitable equivalent circuit for extracting the analytical parameter (usually $R_{c t}$ in faradaic impedance and capacitance in nonfaradaic approach), and the need of initial presumption in fitting analysis are the limiting factors for these assays.

In this paper we overcome these limiting factors by extending immittance function electroanalysis and its applicability to glycoprotein-lectin assays for both highly sensitive glycoprotein detection and glycoprotein-lection interaction quantification without the requirement of equivalent circuit models or analysis of equivalent circuit parameters. Using this approach, we demonstrated that the time of measurement could be significantly reduced while maintaining high sensitivity below nanomolar limits of detection. Additionally, it was demonstrated that the affinity constant $\left(K_{a}\right)$ can be obtained using any or all of the immittance function parameters, clearly demonstrating the feasibility of this approach in glycoprotein-lection studies and the need for future development of fully automatized and optimized glycoarrays.

\section{Acknowledgments}

This work was supported by the São Paulo state research funding agency (FAPESP), Royal Society and Newton Fund. The authors also acknowledge CNPq (141058/2013-7) and CAPES.

\section{Appendix A. Supplementary material}

Supplementary data associated with this article can be found in the online version at http://dx.doi.org/10.1016/j.bios.2016.04.043.

\section{References}

Adamczyk, B., Tharmalinga, T., Rudd, P.M., 2012. BBA Gen. Subj. 1820 (9), 1347-1353.

Asav, E., Sezgintürk, M.K., 2014. Int. J. Biol. Macromol. 66, 273-280.

Bedatty Fernandes, F.C., Patil, A.V., Bueno, P.R., Davis, J.J., 2015. Anal. Chem. 87 (24), 12137-12144.

Berggren, C., Bjanason, B., Johansson, G., 2001. Electroanalysis 13 (3), 173-180.

Berney, H., 2004. Capacitance affinity biosensors. In: Mirsky, V. (Ed.), Ultrathin

Electrochemical Chemo- and Biosensors. Springer, Berlin Heidelberg, pp. 43-65. Berson, S.A., Yalow, R.S., 2006. Clin. Chim. Acta 369 (2), 125-143.

Bertok, T., Klukova, L., Sediva, A., Kasák, P., Semak, V., Micusik, M., Omastova, M., Chovanová, L., Vlček, M., Imrich, R., Vikartovska, A., Tkac, J., 2013a. Anal. Chem. 85 (15), 7324-7332.

Bertok, T., Sediva, A., Katrlik, J., Gemeiner, P., Mikula, M., Nosko, M., Tkac, J., 2013b. Talanta 108, 11-18.

Bohunicky, B., Mousa, S.A., 2011. Nanotechnol. Sci. Appl. 4, 1-10.

Bueno, P.R., Davis, J.J., 2014a. Anal. Chem. 86 (4), 1977-2004.

Bueno, P.R., Davis, J.J., 2014b. Anal. Chem. 86 (3), 1337-1341.

Bueno, P.R., Feliciano, G.T., Davis, J.J., 2015. Phys. Chem. Chem. Phys. 17 (14), 9375-9382.

Bueno, P.R., Mizzon, G., Davis, J.J., 2012. J. Phys. Chem. B 116 (30), 8822-8829.

Carvalho, F., Martins, D., Santos, A., Roque-Barreira, M.-C., Bueno, P., 2014. Biosensors 4 (4), 358-369.

Carvalho, F.C., Soares, S.G., Tamarozzi, M.B., Rego, E.M., Roque-Barreira, M.-C., 2011. PLoS One 6 (11), e27892.

Chen, S., Li, L., Zhao, C., Zheng, J., 2010. Polymer 51 (23), 5283-5293.

Chiriaco, M.S., Primiceri, E., Montanaro, A., de Feo, F., Leone, L., Rinaldi, R., Maruccio, G., 2013. Analyst 138 (18), 5404-5410.

Clark, D., Mao, L., 2012. Dis. Markers 33 (1), 1-10.

Dam, T.K., Brewer, C.F., 2002. Chem. Rev. 102 (2), 387-430.

Daniels, J.S., Pourmand, N., 2007. Electroanalysis 19 (12), 1239-1257.

Dennis, J.W., Granovsky, M., Warren, C.E., 1999. BioEssays 21 (5), 412-421.

Dias, W.B., Hart, G.W., 2007. Mol. BioSyst. 3 (11), 766-772.

Dwek, R.A., 1996. Chem. Rev. 96 (2), 683-720.

Fang, F., Satulovsky, J., Szleifer, I., 2005. Biophys. J. 89 (3), 1516-1533.

Fernandes, F.C.B., Góes, M.S., Davis, J.J., Bueno, P.R., 2013. Biosens. Bioelectron. 50, $437-440$.

Fernandes, F.C.B., Santos, A., Martins, D.C., Góes, M.S., Bueno, P.R., 2014. Biosens. Bioelectron. 57, 96-102.

Foo, K.Y., Hameed, B.H., 2010. Chem. Eng. J. 156 (1), 2-10.

Giménez-Romero, D., Bueno, P.R., Pesquero, N.C., Monzó, I.S., Puchades, R., Maquieira, Á., 2013. J. Phys. Chem. B 117 (28), 8360-8369.

Goes, M.S., Rahman, H., Ryall, J., Davis, J.J., Bueno, P.R., 2012. Langmuir 28 (25), 9689-9699.

Homola, J., Yee, S.S., Gauglitz, G., 1999. Sens. Actuators B-Chem. 54 (1-2), 3-15.

Hu, Y.F., Zuo, P., Ye, B.C., 2013. Biosens. Bioelectron. 43, 79-83.

Höök, F., Kasemo, B., 2007. The QCM-D technique for probing biomacromolecular recognition reactions. In: Janshoff, A., e Steinem, C. (Eds.), Piezoelectric Sensors 5(12). Springer, Berlin Heidelberg, pp. 425-447.

Johari-Ahar, M., Rashidi, M.R., Barar, J., Aghaie, M., Mohammadnejad, D., Ramazani, A., Karami, P., Coukos, G., Omidi, Y., 2015. Nanoscale 7 (8), 3768-3779.

Laurent, N., Voglmeir, J., Flitsch, S.L., 2008. Chem. Commun. 37, 4400-4412. 
Lebed, K., Kulik, A.J., Forró, L., Lekka, M., 2006. J. Colloid Interface Sci. 299 (1), 41-48. Lehr, J., Fernandes, F.C.B., Bueno, P.R., Davis, J.J., 2014. Anal. Chem. 86 (5), 2559-2564.

Lisdat, F., Schäfer, D., 2008. Anal. Bioanal. Chem. 391 (5), 1555-1567.

Long, G.L., Winefordner, J.D., 1983. Anal. Chem. 55 (7), 712-724.

Lourenço, E.V., Bernardes, E.S., Silva, N.M., Mineo, J.R., Panunto-Castelo, A., RoqueBarreira, M.-C., 2006. Microb. Infect. 8 (5), 1244-1251.

Love, J.C., Estroff, L.A., Kriebel, J.K., Nuzzo, R.G., Whitesides, G.M., 2005. Chem. Rev. 105 (4), 1103-1170.

Luo, X., Davis, J.J., 2013. Chem. Soc. Rev. 42 (13), 5944-5962.

Marchant, J., Cowper, B., Liu, Y., Lai, L., Pinzan, C., Marq, J.B., Friedrich, N., Sawmynaden, K., Liew, L., Chai, W., Childs, R.A., Saouros, S., Simpson, P., Roque Barreira, M.C., Feizi, T., Soldati-Favre, D., Matthews, S., 2012. J. Biol. Chem. 287 (20), $16720-16733$

Marques, S.M., Santos, A., Gonçalves, L.M., Sousa, J.C., Bueno, P.R., 2015. Electrochim. Acta 182, 946-952.

Mayeux, R., 2004. NeuroRX 1 (2), 182-188.

Mihara, H., Tomizaki, K., Usui, K., 2010. FEBS J. 277 (9), 1996-2005.

Monteiro, V.G., Sares, C.P., De Souza, W., 1998. FEMS Microbiol. Lett. 164 (2), 323-327.

Nakamura-Tsuruta, S., Uchiyama, N., Peumans, W.J., Van Damme, E.J.M., Totani, K., Ito, Y., Hirabayashi, J., 2008. FEBS J. 275 (6), 1227-1239.

Nelson, L., Cox, M.M., 2012. Lehninger principles of biochemistry. Freeman W.H. \& Company.

Patil, A.V., Bedatty Fernandes, F.C., Bueno, P.R., Davis, J.J., 2015. Anal. Chem. 87 (2), 944-950.

Pedroso, M.M., Watanabe, A.M., Roque-Barreira, M.C., Bueno, P.R., Faria, R.C., 2008. Microchem. J. 89 (2), 153-158.

Pereira-Da-Silva, G., Carvalho, F.C., Roque-Barreira, M.C., 2012. Inflamm. Allergy Drug Targets 11 (6), 433-441.

Pesquero, N.C., Pedroso, M.M., Watanabe, A.M., Goldman, M.H.S., Faria, R.C., RoqueBarreira, M.C., Bueno, P.R., 2010. Biosens. Bioelectron. 26 (1), 36-42.

Pierce, M.M., Raman, C.S., Nall, B.T., 1999. Methods 19 (2), 213-221.

Rabe, M., Verdes, D., Seeger, S., 2011. Adv. Colloid Interface Sci. 162 (1-2), 87-106. Ramburth, N.D.S., Dwek, M.V., 2011. Acta Histochem. 113 (6), 591-600.

Reddy, P.J., Sadhu, S., Ray, S., Srivastava, S., 2012. Clin. Lab. Med. 32 (1), 47-72.

Reis, C.A., Osorio, H., Silva, L., Gomes, C., David, L., 2010. J. Clin. Pathol. 63 (4), 322-329.

Ronkainen, N.J., Halsall, H.B., Heineman, W.R., 2010. Chem. Soc. Rev. 39 (5),
1747-1763.

Rosa, J.C., Greene, L.J., De Oliveira, P.S.L., Garratt, R., Beltramini, L., Resing, K., RoqueBarreira, M.-C., 1999. Prot. Sci. 8 (1), 13-24.

Rusling, J.F., Kumar, C.V., Gutkind, J.S., Patel, V., 2010. Analyst 135 (10), 2496-2511. Safina, G., Duran, I.B., Alasel, M., Danielsson, B., 2011. Talanta 84 (5), 1284-1290.

Santos, A., Carvalho, F.C., Roque-Barreira, M.-C., Bueno, P.R., 2014a. Biosens. Bioelectron. 62, 102-105.

Santos, A., Carvalho, F.C., Roque-Barreira, M.-C., Zorzetto-Fernandes, A.L., GimenezRomero, D., Monzó, I., Bueno, P.R., 2015a. Langmuir 31 (44), 12111-12119.

Santos, A., Davis, J.J., Bueno, P.R., 2014b. J Anal Bioanal Tech. S7:016. http://dx.doi. org/10.4172/2155-9872.S7-016.

Santos, A., Piccoli, J.P., Santos-Filho, N.A., Cilli, E.M., Bueno, P.R., 2015b. Biosens. Bioelectron. 68, 281-287.

Santos-de-Oliveira, R., Dias-Baruffi, M., Thomaz, S.M., Beltramini, L.M., Roque-Barreira, M.C., 1994. J. Immunol. 153 (4), 1798-1807.

Silva, M.L.S., 2015. BBA Rev. Can. 1856 (2), 165-177.

Speight, R.E., Cooper, M.A., 2012. J. Mol. Recognit. 25 (9), 451-473.

Straus, W., 1981. Histochemistry 73 (1), 39-47.

Strimbu, K., Tavel, J.A., 2010. Curr. Opin. HIV Aids 5 (6), 463-466.

Su, L., Zou, L., Fong, C.-C., Wong, W.-L., Wei, F., Wong, K.-Y., Wu, R.S.S., Yang, M., 2013. Biosens. Bioelectron. 46, 155-161.

Surinova, S., Choi, M., Tao, S., Schüffler, P.J., Chang, C.Y., Clough, T., Vysloužil, K., Khoylou, M., Srovnal, J., Liu, Y., Matondo, M., Hüttenhain, R., Weisser, H., Buhmann, J.M., Hajdúch, M., Brenner, H., Vitek, O., Aebersold, R., 2015. EMBO Mol. Med. 7 (9), 1166-1178.

Takeda, Y., Matsuo, I., 2014. Isothermal calorimetric analysis of lectin-sugar interaction. In: Hirabayashi, J. (Ed.), Lectins 1200(18). Springer, New York, pp. 207-214.

Taleat, Z., Cristea, C., Marrazza, G., Mazloum-Ardakani, M., Săndulescu, R., 2014. J. Electroanal. Chem. 717-718, 119-124.

Tkac, J., Davis, J.J., 2008. J. Electroanal. Chem. 621 (1), 117-120.

Uludag, Y., Tothill, I.E., 2012. Anal. Chem. 84 (14), 5898-5904.

Voller, A., Bartlett, A., Bidwell, D.E., 1978. J. Clin. Pathol. 31 (6), 507-520.

Wang, J., 2006. Biosens. Bioelectron. 21 (10), 1887-1892.

Wiseman, M.E., Frank, C.W., 2012. Langmuir 28 (3), 1765-1774.

Yakovleva, M.E., Safina, G.R., Danielsson, B., 2010. Anal. Chim. Acta 668, 80-85.

Yang, P., Li, X., Wang, L., Wu, Q., Chen, Z., Lin, X., 2014. J. Electroanal. Chem. 732, 38-45.

Zachara, N.E., Hart, G.W., 2006. BBA Mol. Cell Biol. Lipids 1761 (5-6), 599-617. 